\title{
Protein-Energy Intake, Sleep Quality and Quati
Life Before and After Bariatric Surgery: The Malaysian Context
}

\author{
Tsen Poh Yue ${ }^{1}$, Tikfu Gee ${ }^{2}$, Raflis Ruzairee Awang ${ }^{3}$, Barakatun Nisak Binti Mohd Yusof ${ }^{1}$, \\ Lim Shu Yu ${ }^{2}$, Ang Yeu Leng ${ }^{1}$, Soo Jia Ying ${ }^{2}$, Lee Yu Wei ${ }^{2}$ \\ ${ }^{1}$ Department of Nutrition and Dietetics, Faculty of Medicine and Health Sciences, Universiti Putra Malaysia, \\ Selangor Darul Ehsan Malaysia \\ ${ }^{2}$ Department of Surgery, Faculty of Medicine and Health Sciences, Universiti Putra Malaysia, \\ Selangor Darul Ehsan Malaysia \\ ${ }^{3}$ Department of Surgery, Hospital Kuala Lumpur
}

*Corresponding author - Tsen Poh Yue, groupesantesoin@gmail.com

Received 30 January 2019;

Accepted 20 February 2019;

Published 24 February 2019

\begin{abstract}
Background: This prospective observational study aimed to determine the impact of bariatric surgery on the protein-energy intake, sleep quality and quality of life (QOL) of bariatric surgery patients in Malaysia. Methods: The study evaluated 52 morbidly obese patients who underwent bariatric surgery. The short version of the World Health Organization Quality of Life questionnaire (WHOQOL-BREF), Epworth Sleepiness Scale (ESS) questionnaire and three days 24-hour diet recall were used to evaluate the health-related QOL, sleep quality and protein-energy intake of patients. Patients were interviewed before and 3 months after surgery. Results: The mean age was 42 years and $69.2 \%$ of them were female. The mean BMI was $42 \mathrm{~kg} / \mathrm{m} 2$. Patients with morbid obese had significantly lowered QOL scores, mean intake of 1898 kilocalories and $75 \mathrm{~g}$ protein per day before the surgery. The reduction of weight after bariatric surgery showed an increase in QOL score in all areas (P < 0.05$)$ and a decrease on ESS score from $6.3 \pm 4.0$ to $2.9 \pm 2.3$ ( $\mathrm{p}<0.00$ ). The mean intake 3 months after surgery was 718 kilocalories, $39 \mathrm{~g}$ protein per day. Conclusion: Bariatric surgery is proven effective in achieving significant weight loss, improving sleep quality and QOL among Malaysian obese patients within 3 months of surgery. However, the newly restricted stomach after bariatric surgery significantly reduces food intake in the first 3 months. Therefore, a more careful follow-up with patients is required.
\end{abstract}

Keywords: Bariatric surgery, Protein-energy intake, Quality of life, Morbid obesity, Sleep quality

\section{Introduction}

Obesity, a chronic disease characterized by abnormal or excessive fat accumulation, has become a major health problem in both developed and developing countries ${ }^{[1]}$. Malaysia, a multi-ethnic middle-income nation has enjoyed one of the best economic growth records in Asia causing her to experience a rapid phase of industrialization and urbanization ${ }^{[2]}$. The accelerated demographic and nutrition transition towards achieving a developed economy status has inevitably generated marked changes in dietary habits and lifestyles of Malaysians. In fact, the National Health and Morbidity Survey done in 2015 showed a significant rise in the prevalence of obesity in the adult Malaysian population from $4.4 \%$ to $17.7 \%$ in just a short span of 2 decades ${ }^{[3]}$. The rapid rise in prevalence and incidence of obesity in this country has imposed a heavy burden on the health care system and lowered the quality of life (QOL) among the obese population.

Compared with conventional lifestyle intervention of diet and exercise for body weight management, bariatric surgery is currently the most effective treatment for prolonged weight reduction and improvement of obesity-related conditions such as dyspnea, obstructive sleep apnea (OSA), type 2 diabetes mellitus (T2DM), hypertension, lipid profile, glucometabolic control and sleep quality ${ }^{[4-7]}$. Health-related QOL, which was significantly impaired with the rise of obesity was also shown to improve with bariatric surgery ${ }^{[8]}$. The indication of bariatric surgery for Asian patients based on the Asia-Pacific Bariatric Surgery Group consensus meeting in the year 2005 was BMI $>37 \mathrm{~kg} / \mathrm{m} 2$ or $>32$ $\mathrm{kg} / \mathrm{m} 2$ with diabetes or two other obesity-related co-morbidities ${ }^{[2]}$. A "success" weight loss outcomes is described as a loss of $>50 \%$ 
excess weight, loss of $>20-30 \%$ of initial weight and achieving a BMI $<35 \mathrm{~kg} / \mathrm{m} 2^{[9]}$.

Bariatric surgery procedures are traditionally divided into purely restrictive, malabsorptive, or combined procedures. Restrictive procedures include sleeve gastrectomy (SG) and adjustable gastric banding (AGB); malabsorptive procedures include billiopancreatic diversion (BPD) and BPD with duodenal switch; and restrictivemalabsorptive procedures includes Roux-en-Y Gastric Bypass (RYGB). The change in the anatomy and physiology of the gastrointestinal structure after bariatric procedure changes the quality and quantity of diet. In fact, nutrition deficiency among patients undergoing malabsorptive procedure is more due to the alteration of intestinal motility, absorptive, digestive and neuroendocrine functions ${ }^{[10]}$.

Emerging studies have been done in Asia looking at the changes of health-related QOL overtime after undergoing bariatric surgery. However to the best of our knowledge, there was no study done in Malaysia on protein-energy intake, sleep quality and health-related QOL after bariatric surgery ${ }^{[2]}$. The increasing popularity of bariatric surgery among Malaysians due to the alarming rise of obesity rate demands more to be conducted in this area for proper postoperative management care. Therefore, the primary aim of this study is to evaluate the impact of bariatric surgery on the healthrelated QOL among patients before and 3 months after bariatric surgery. Also, this study aims to assess the protein and energy intake and sleep quality of bariatric surgery patients before and after bariatric surgery in Malaysia.

\section{Methods}

A prospective cohort study was conducted among patients age between 18 to 65 years going for elective bariatric surgery in the Bariatric clinic of Hospital Kuala Lumpur, Malaysia. Criteria included diagnosis of morbid obesity patients with BMI > 37 $\mathrm{kg} / \mathrm{m} 2$ or $>32 \mathrm{~kg} / \mathrm{m} 2$ with diabetes or two other obesity-related comorbidities. The exclusion criteria include the patient that are illiterate, unable to be fed orally, have logistic issue with difficulty in complying with the post-operation close monitoring and followup, who has psychiatric disorder (depression, substance abuse, eating disorder, alcoholism, dementia etc.) and unable to give informed consent.

All patients who underwent elective bariatric surgery early 2018 went through a multidisciplinary evaluation and was interviewed, attended, and counselled by a dietitian before scheduled surgery and again during follow-up examinations after surgery. Routine assessment of patients' information such as patients' sociodemographic characteristics; clinical information; anthropometric measurements; biochemical data; dietary history using a 3 days 24-hour dietary recall; ESS questionnaire, and QOL assessment using short version of the WHOQOL-BREF questionnaire were ascertained and recorded through verbal interview during each patient visit.

WHOQOL-BREF is a self-completed questionnaire that was used to evaluate QOL among the study patients. The translated and validated Malaysian WHOQOL-BREF contains 25 items; the first two questions evaluate patient's self-perceived QOL and satisfaction with health ${ }^{[11]}$. The remaining questions represent the four domains: physical health, psychological, social relationships and environment ${ }^{[12]}$. Each item is scored from 1 to 5 points and a higher score is considered to indicate a better quality of life. As the numbers of items are different for each domain, the domain scores are calculated by multiplying the average of the scores of all items in the domain by the same factor of four. Therefore, each domain score has the same range, from 4 to 20 .

Patients were also asked to fill up the translated ESS questionnaire before and 3 months after surgery. The ESS is a validated selfreported eight-item questionnaire used to measure daytime sleepiness ${ }^{[13]}$. The questions are based on the patient's probability of dozing with a scale of increasing probability from 0 to 3 for 8 different hypothetical situations during their daily life. A total ESS score of $<10$ is considered to be within normal range while scores of $\geq 10$ indicate excessive daytime sleepiness and scores of between 16 and 24 indicates a high level of daytime sleepiness. BMI was calculated using the standard formula of weight divided by the square of the height. The weight loss progress was calculated in percent excess weight loss $(\% \mathrm{EWL})^{[14]}$. The \%EWL was calculated as described as: $\% \mathrm{EWL}=[($ Operative weight follow up weight)/ideal weight] $\times 100]$

Statistical Package for Social Sciences (SPSS) version 22 was used for statistical analysis and data interpretation. Continuous variables were presented in means and standard deviations (SD) while categorical variables were expressed as frequencies and percentages. T-test was used to compare assessments across time for continuous variables. Paired t-test was used to compare the variables in the preoperative and postoperative period. Repeated Measures ANOVA was used to test between-subject effect among WHOQOL-BREF domains and other variables. The strength of association was calculated by a proportion at $95 \%$ confidence interval. For all analyses, a p-value $<0.05$ was regarded as statistically significant in this study.

\section{Results}

Out of the 73 patients recruited, only 52 patients were evaluated in the study. The mean age of patients was $42 \pm 10.5$ years with $69.2 \%$ were female and $30.8 \%$ were male (Table 1 ). About $75 \%$ of patients underwent LSG follow by RYGB (21.2\%) and single anastomosis duodenojejunal bypass with sleeve gastrectomy (SADJB) (3.8\%). The mean BMI before surgery was $42 \mathrm{~kg} / \mathrm{m} 2$ $( \pm 8.6 \mathrm{~kg} / \mathrm{m} 2)$ with $48.1 \%$ of patient in BMI class of more than 37.5 $\mathrm{kg} / \mathrm{m} 2$. Type 2 diabetes mellitus was presented in $25.6 \%$ of our study population, $29.3 \%$ was with hypertension and $30.5 \%$ with dyslipidemia. The biochemical data show that the total protein is $75.2 \pm 5.44 \mathrm{~g} / \mathrm{l}$ and the serum albumin is $40.2 \pm 5.3 \mathrm{~g} / \mathrm{l}$. The mean intake of our study population before surgery was $1898 \pm 496$ kilocalories and $75 \pm 22.7 \mathrm{~g}$ of protein per day.

Three months after bariatric surgery, the \%EWL of our study population was found to be $26.4 \%$ (Table 2). The biochemical data show no significant changes to the total protein $(\mathrm{p}<0.629)$ and serum albumin $(\mathrm{p}<0.058) 3$ months after bariatric surgery. Besides that, the mean intake 3 months after bariatric surgery was $718 \pm 159$ kilocalories, $39 \pm 12.3 \mathrm{~g}$ protein per day. This study found that the total hours of sleep of our study population is $6.5 \pm$ 1.5 hours before surgery and $6.7 \pm 1.3$ three months after surgery. The ESS showed a significant improvement of $37 \%(\mathrm{p}<0.000)$ after bariatric surgery. Table 3 compared the average percent change of WHOQOL-BREF score for the four domains, the overall quality of life question and general health question for the patients before and 3 months after bariatric surgery. There is a significant 
change of $9 \%$ in the physical domain ( $\mathrm{p}<0.000$ ), $8.1 \%$ in the psychosocial domain $(\mathrm{p}<0.000), 4.2 \%$ in the social environmental domain $(\mathrm{p}<0.002)$, and $3.6 \%$ in the environment domain $(\mathrm{p}<$ $0.000) 3$ months after bariatric surgery. There was a change of $11.7 \%$ in the overall quality of life question $(p<0.018)$ and $26.2 \%$ in the general health question $(\mathrm{p}<0.000) 3$ months after bariatric surgery.

Table 1: Characteristic of study population $(n=52)$

\begin{tabular}{|c|c|}
\hline Characteristics & $\mathbf{n}=52$ \\
\hline \multicolumn{2}{|l|}{ Gender (\%) } \\
\hline Female & 69.2 \\
\hline Male & 30.8 \\
\hline Age (mean years \pm SD) & $42 \pm 10.5$ \\
\hline$<35(\%)$ & 26.9 \\
\hline$>35(\%)$ & 73.1 \\
\hline \multicolumn{2}{|l|}{ Race $(\%)$} \\
\hline Chinese & 13.5 \\
\hline Malay & 46.2 \\
\hline Indian & 9.6 \\
\hline Others & 30.8 \\
\hline \multicolumn{2}{|l|}{ Marital status (\%) } \\
\hline Married & 71.2 \\
\hline Single & 25.0 \\
\hline Divorced & 1.9 \\
\hline Widowed & 1.9 \\
\hline \multicolumn{2}{|l|}{ Co-morbidities (\%) } \\
\hline Type 2 Diabetes Mellitus $(n=21)$ & 25.6 \\
\hline Hypertension $(n=24)$ & 29.3 \\
\hline Dyslipidaemia $(\mathrm{n}=25)$ & 30.5 \\
\hline Preoperative BMI (mean $\left.\mathrm{kg} / \mathrm{m}^{2} \pm \mathrm{SD}\right)$ & $42 \pm 8.6$ \\
\hline \multicolumn{2}{|l|}{ Preoperative BMI class (\%) } \\
\hline Obese class $1: 27.5-32.4 \mathrm{~kg} / \mathrm{m}^{2}$ & 11.5 \\
\hline Obese class $2: 32.5-37.4 \mathrm{~kg} / \mathrm{m}^{2}$ & 23.1 \\
\hline Obese class $3: \geq 37.5 \mathrm{~kg} / \mathrm{m}^{2}$ & 48.1 \\
\hline Super obese $\geq 50 \mathrm{~kg} / \mathrm{m}^{2}$ & 17.3 \\
\hline \multicolumn{2}{|l|}{ Type of surgery $(\%)$} \\
\hline LSG & 75.0 \\
\hline RYGB & 21.2 \\
\hline SADJB & 3.8 \\
\hline
\end{tabular}

SD: standard deviation, BMI: body mass index, LSG: laparoscopic sleeve gastrectomy, RYGB: Roux-En-Y gastric bypass, SADJB: single anastomosis duodeno jejunal bypass with sleeve gastrectomy

Table 2: Comparison of body mass index before and 3 months after bariatric surgery

\begin{tabular}{ccccc}
\hline Parameters & $\begin{array}{c}\text { Before } \\
\text { surgery } \\
(\mathbf{n = 5 2})\end{array}$ & $\begin{array}{c}\text { 3 months } \\
\text { after surgery } \\
(\mathbf{n = 5 2})\end{array}$ & $\begin{array}{c}\text { P- } \\
\text { value }\end{array}$ & $\begin{array}{c}\text { Average } \\
\text { percent } \\
\text { change }\end{array}$ \\
\hline $\mathrm{BMI}\left(\mathrm{kg} / \mathrm{m}^{2}\right)$ & $42 \pm 8.6$ & $35 \pm 7.4$ & $0.000^{*}$ & 9.0 \\
$\% \mathrm{EWL}$ & & & & 26.4 \\
\hline
\end{tabular}

BMI: body mass index, \%EWL: Percent Excess Weight Loss

${ }^{*} p<0.05$ is significant

*Paired sample test

*Ideal body weight BMI 25

Repeated measures ANOVA was used to test the between-subject effect among WHOQOL-BREF domains and different parameters (Table 4). The finding shows no statistically significant differences between different gender and the type of surgery on all WHOQOLBREF domains before and 3 months after bariatric surgery. Race, preoperative BMI and postoperative BMI show a significant difference in the physical health questions $(p<0.05)$ and environment questions $(p<0.05)$. Marital status $(p<0.047)$ and preoperative BMI class $(\mathrm{p}<0.027)$ shows significant difference in the psychosocial questions.

Table 3: Comparison of WHOQOL-BREF parameters with average percent change before and 3 months after bariatric surgery

\begin{tabular}{lcccc}
\hline $\begin{array}{l}\text { WHOQOL- } \\
\text { BREF } \\
\text { parameters }\end{array}$ & $\begin{array}{c}\text { Before } \\
\text { surgery }\end{array}$ & $\begin{array}{c}\text { 3 months } \\
\text { after } \\
\text { surgery }\end{array}$ & $\begin{array}{c}\text { p- } \\
\text { value }\end{array}$ & $\begin{array}{c}\text { Average } \\
\text { percent } \\
\text { change }\end{array}$ \\
\hline Overall QOL & $3.4 \pm 1.1$ & $4.3 \pm 0.6$ & $0.018^{*}$ & 11.7 \\
General & $2.4 \pm 1.1$ & $4.1 \pm 0.7$ & $0.000^{*}$ & 26.2 \\
health & & & & \\
Physical & $13.7 \pm 3.0$ & $16.7 \pm 1.7$ & $0.000^{*}$ & 9.0 \\
Psychosocial & $13.6 \pm 2.3$ & $16.0 \pm 1.9$ & $0.000^{*}$ & 8.1 \\
Social & $13.5 \pm 2.7$ & $14.7 \pm 2.8$ & $0.002^{*}$ & 4.2 \\
Environment & $14.6 \pm 2.5$ & $15.7 \pm 2.0$ & $0.000^{*}$ & 3.6 \\
*p < 0.05 is significant & & & \\
*Paired sample test & & &
\end{tabular}

Table 4: Repeated Measures ANOVA used to test between subject effect among WHOQOL-BREF domains and parameters

\begin{tabular}{lcccc}
\hline \multirow{2}{*}{ Parameters } & \multicolumn{4}{c}{ P value } \\
\cline { 2 - 5 } & Physical & $\begin{array}{c}\text { Psycho } \\
\text { social }\end{array}$ & Social & $\begin{array}{c}\text { Enviro } \\
\text { nment }\end{array}$ \\
\hline Gender & 0.270 & 0.915 & 0.138 & 0.430 \\
Age & 0.708 & 0.392 & 0.744 & 0.948 \\
Race & $0.032^{*}$ & 0.832 & 0.187 & $0.009^{*}$ \\
Marital status & 0.906 & $0.047^{*}$ & 0.246 & 0.221 \\
$\begin{array}{l}\text { Preoperative BMI } \\
\text { class }\end{array}$ & $0.004^{*}$ & $0.027^{*}$ & 0.101 & $0.001^{*}$ \\
$\begin{array}{l}\text { Postoperative } \\
\text { BMI class }\end{array}$ & $0.002^{*}$ & 0.162 & 0.206 & $0.000^{*}$ \\
Type of surgery & 0.629 & 0.801 & 0.590 & 0.073 \\
\hline
\end{tabular}

\section{Discussion}

This study was carried out to evaluate the protein-energy intake, sleep quality and health-related QOL of patients before and 3 months after bariatric surgery in Malaysia. In a nutshell, the results indicated a significant improvement on the health-related QOL and sleep quality after bariatric surgery. In our series, all four domains of health evaluated using the WHOQOL-BRIEF questionnaire showed a significant improvement with percent excess weight loss (\%EWL) of $26.4 \%$ in 3 months after bariatric surgery (Table 3 ). Results also showed a significant improvement especially in areas such as "activities of daily living", "dependence on medicinal substances", "mobility", "pain and discomfort", "sleep quality", "work capacity", "self-esteem" and "body image" with weight loss after the surgery. Besides that, the result showed that there is a significant improvement in the ESS score despite no significant difference with the total hours of sleep before and after surgery.

The results observed are consistent with other similar studies that have shown that QOL significantly improved in all areas (physical health, mental health, social relations, and environment) as soon as 3 months following bariatric surgery ${ }^{[8],[15],[16]}$. Buzgova et al., 2014 in his study of 76 morbidly obese patients who underwent LSG showed a significant increase of QOL in all indicated areas in 3 
and 6 months following surgery ${ }^{[16]}$. It is also known in the literature that obese individuals are more likely to suffer physical, emotional and psychological health issue due to social discrimination, poor image of self and guilt or embarrassment due to low productivity ${ }^{[4],[8],[16]-[19]}$. Obesity not only caused oneself to be less confident, socially inactive and emotionally unstable, it also interferes with sleep quality and duration ${ }^{[19]}$.

Bariatric surgery however shows a significant association with improvements in sleep quality, excessive daytime sleepiness (EDS) and the risk of OSA 3-6 months after surgery ${ }^{[5],[7]}$. Toor et al., 2012 in his study also noted a significant improvement in sleep duration from 6.0 to $6.8 \mathrm{~h}(\mathrm{p}<0.0001) 3$ to 12 months after surgery ${ }^{[7]}$. According to Pinto et al., bariatric surgery was shown to have a beneficial impact on sleep quality and EDS, and that indirectly resulted in an improvement in depressive symptoms ${ }^{[6]}$. In his study showed that bariatric surgery improved ESS $(8.1 \pm 4.7$ versus $6.0 \pm$ $3.3 ; \mathrm{p}<0.001$ ). Twelve of the 18 subjects with baseline EDS (ESS $\geq 10$ ) developed normal ESS score after surgery. In addition, the QOL in patients with OSA showed remarkable improvement after bariatric surgery as well ${ }^{[20]}$.

With the major concerns associated with protein-energy malnutrition after bariatric procedures, bariatric surgery patients were advised to take at least $60 \mathrm{~g} / \mathrm{day}$ and up to $1.5 \mathrm{~g} / \mathrm{kg}$ ideal body weight per day to be considered as adequate ${ }^{[21],[22]}$. Nevertheless, the scientific evidence supporting this recommendation and its relationship with lean mass preservation and protein status during bariatric surgery-induced weight loss are considered weak ${ }^{[21]}$. The data from this study showed that protein intake is below the current recommendations (>60 g/day). Although there was a significant reduction in consumption, there was no substantial reduction in total blood protein and serum albumin after bariatric surgery. To support this finding, it was reported a lower than recommended mean total protein intake of 37-46 g/day at 3 months and 47-58 $\mathrm{g} /$ day at 12 months after bariatric surgery ${ }^{[23],[24]}$. Although many researches have suggested patients to consume protein 60-80 g/day in the early postoperative phase, meeting the daily reference intake of $46-58 \mathrm{~g} / \mathrm{day}$ is a more realistic amount of protein for patients to consume and it should be sufficient to prevent malnutrition in the later postoperative phases ${ }^{[25]}$.

In conclusion, bariatric surgery is proven effective in achieving significant weight loss, improving sleep quality and QOL among Malaysian obese patients within 3 months of surgery. Interestingly, a decrease in food intake after the surgery did not significantly affect the serum protein and serum albumin. Although there is no significant decrease in the serum albumin, the food intake was greatly reduced due to the newly restricted stomach. Therefore, vigilant care by the health care professionals involved in bariatric patient care for these patients is required especially in the early stages after bariatric surgery. Establishing a good eating habit at the early stages will prevent patients from poor eating habits after bariatric surgery. Nonetheless, long-term observational studies are anticipated to show both short and long-term progress of bariatric surgery on food intake, sleep quality and QOL for obese Malaysian population.

\section{References}

[1] Finucane MM, Stevens GA, Cowan MJ, et al. Global Burden of Metabolic Risk Factors of Chronic Diseases Collaborating Group (Body Mass Index). National, regional, and global trends in body-mass index since 1980: systematic analysis of health examination surveys and epidemiological studies with 960 country-years and 9.1 million participants. Lancet 2011; 377:557-567.

[2] Lee WJ, Wang W. Bariatric surgery: Asia-Pacific perspective. Obes Surg 2005; 15: 751-757.

[3] Institute for Public Health (IPH). National Health and Morbidity Survey 2015 (NHMS 2015). Vol. 2: NonCommunicable Diseases, Risk Factors \& Other Health Problems; 2015

[4] Douglas I, Bhaskaran K, Batterham R, Smeeth L. Bariatric Surgery in the United Kingdom: A Cohort Study of Weight Loss and Clinical Outcomes in Routine Clinical Care. PLOS Medicine, 2015; 12(12):e1001925.

[5] Dilektasli E, Dilektasli A. Laparoscopic Sleeve Gastrectomy Improves Excessive Daytime Sleepiness and Sleep Quality 6 Months Following Surgery: A Prospective Cohort Study. Advances in Therapy, 2016; 33(5):774-785.

[6] Pinto T, de Bruin P, de Bruin V, Lopes P, Lemos F. Obesity, Hypersomnolence, and Quality of Sleep: the Impact of Bariatric Surgery. Obesity Surgery, 2017; 27(7):1775-1779.

[7] Toor P, Kim K, Buffington CK. Sleep Quality and Duration Before and After Bariatric Surgery. Obesity Surgery, 2012; 22(6):890-895.

[8] Chang CY, Hung CK, Chang YY, et al. Health related Quality of Life in Adult Patients with Morbid Obesity Coming for Bariatric Surgery. Obes Surg, 2010; 20:1121-1127.

[9] Halverson JD, Koehler RE. Gastric bypass: analysis of weight loss and factors determining success. Surgery, 1981; 90(3):446-55.

[10] Kushner RF. Micronutrient deficiencies and bariatric surgery. Curr Opin Endocrinol Diabetes, 2006; 13: 40511.

[11] Abdullah L. Validation of an Instrument for Measuring Quality of Life amongst Malaysian Youth. Modern Applied Science, 2014; 8(2):22-35.

[12] Development of the World Health Organization WHOQOL-BREF quality of life assessment. The WHOQOL Group. Psychol Med, 1998; 28:551-558.

[13] Johns MW. About the ESS - Epworth Sleepiness Scale [Internet]. 1990 [cited 28 February 2018]. Available from: http://epworthsleepinessscale.com/about-the-ess/

[14] Deitel M, Greenstein RJ. Recommendations for reporting weight loss. Obes Surg, 2003; 13: 159-60.

[15] Brunault P, Jacobi D, Léger J, Bourbao-Tournois C, Huten N, Camus V et al. Observations Regarding 'Quality of Life' and 'Comfort with Food' After Bariatric Surgery: Comparison Between Laparoscopic Adjustable Gastric Banding and Sleeve Gastrectomy. Obesity Surgery, 2011;21(8):1225-1231.

[16] Buzgova R, Buzga M, Holeczy P. Health-related quality of life in morbid obesity: the impact of laparoscopic sleeve gastrectomy. Cent Eur J Med, 2014; 9(3), 374381.

[17] Tarride J, Breau R, Sharma A, et al. The Effect of Bariatric Surgery on Mobility, Health-Related Quality of Life, Healthcare Resource Utilization, and Employment Status. Obesity Surgery, 2016; 27(2):349-356.

[18] Obesity and overweight [Internet]. World Health Organization. 2018 [cited 22 February 2018]. Available 
from:

http://www.who.int/mediacentre/factsheets/fs311/en/

[19] Son YJ, Kim G. The relationship between obesity, selfesteem and depressive symptoms of adult women in Korea. The Korean Journal of Obesity, 2012; 21(2):8998.

[20] de Raaff C, Coblijn U, de Klerk E, et al. Impact of obstructive sleep apnea on quality of life after laparoscopic Roux-en-Y gastric bypass. The Surgeon, 2017; 16(3): 1 - 5.

[21] Mechanick JI, Youdim A, Jones DB, et al. Clinical practice Guidelines for the Perioperative Nutritional, Metabolic, and Nonsurgical Support of the Bariatric Surgery Patient-2013 Update: Cosponsored by American Association of Clinical Endocrinologists, The Obesity Society, and American Society for Metabolic \& Bariatric Surgery. Surgery for Obesity and Related Disease, 2013; 9:159-191.

[22] Dodell GB, Albu JB, Attia L, et al. The Bariatric Surgery Patient: Lost to Follow-up; from Morbid Obesity to
Severe Malnutrition. Endocrine Practice, 2012; 18(2):2125.

[23] Moizé V, Geliebter A, Gluck ME, et al. Obese patients have inadequate protein intake related to protein intolerance up to 1 year following Roux-en-Y gastric bypass. Obes Surg, 2003; 13:23-28.

[24] Bavaresco M, Paganini S, Lima TP, et al. Nutritional course of patients submitted to bariatric surgery. Obes Surg, 2008; 20(6): 716-21.

[25] Isom KA. Standardizing the Evolution of the Postoperative Bariatric Diet. Diabetes Spectrum, 2012; 25(4):222-228.

\section{Declarations}

\subsection{Conflict of Interest}

There is no personal or financial conflict of interest.

\subsection{Financial support}

The study was funded internally with no external support for the research or the writing of the manuscript. 